\title{
Cigarette smoking in adolescents with type 1 diabetes mellitus and congenital adrenal hyperplasia
}

\author{
Pelin Asfuroğlu1, Aslıhan Araslı-Yılmaz², Zehra Aycan² \\ Clinic of ${ }^{2}$ Pediatric Endocrinology and ${ }^{1}$ Department of Pediatrics, University of Health Sciences, Dr. Sami Ulus Obstetrics \\ and Gynecology and Pediatrics Training and Research Hospital, Ankara, Turkey. E-mail: pelinari@gmail.com \\ Received: 8th March 2018, Revised: 9th May 2018, 25th June 2018, Accepted: 3th July 2018
}

SUMMARY: Asfuroğlu P, Araslı-Yılmaz A, Aycan Z. Cigarette smoking in adolescents with type 1 diabetes mellitus and congenital adrenal hyperplasia. Turk J Pediatr 2019; 61: 236-243.

Adolescence is a long period involving many physical and psycho-social changes experienced during transition from childhood to adulthood. In this period, behaviors such as curiosity and risk-taking are common, and cigarette smoking initiation is one of those behaviors. In this study, it was aimed to find out whether chronic diseases are an effective factor or not in the cigarette smoking initiation of adolescents. One-hundred adolescents with Type 1 Diabetes Mellitus (T1DM) and 50 adolescents with Congenital Adrenal Hyperplasia (CAH) aged 12 and above under follow-up at the Pediatric Endocrinology Clinic and 100 healthy adolescents within the same age group who applied to the Adolescent Outpatient Clinic were included in the study. A survey was applied to all of these adolescents, which had been developed by researchers and contained questions about their socio-demographic features and cigarette smoking. Fourteen $(5.6 \%)$ of the 250 adolescents were smokers. The rate of those who tried, but quitted cigarette smoking was found as approximately $20 \%$. Cigarette smoking rate of those with T1DM was $1 \%$, of those with $\mathrm{CAH}$ was $4 \%$, and of the healthy adolescents was $11 \%$. Cigarette smoking was significantly lower in those with a chronic disease $(\mathbf{2 \%})$ than those who were healthy $(11 \%)$. Adolescents' parents and friends had an effect on the cigarette smoking initiation, and adolescents smoked their first cigarette generally because of curiosity.

It was seen in this study that the adolescents with a chronic disease less frequently smoked cigarettes than the healthy adolescents, the rate of cigarette smoking in parents of cigarette smoking adolescents was very high, and their parents and friends had an effect on cigarette smoking initiation of adolescents.

Key words: adolescent, cigarette smoking, type 1 diabetes mellitus, congenital adrenal hyperplasia.

Cigarette smoking is a common public health concern around the world, and is also common among adolescents and adults in Turkey. A majority of adults start cigarette smoking in the adolescence period. Adolescence is a period during which inclination to take risks increases, and cigarette smoking is one of those inclinations. ${ }^{1,2}$

Main reasons for the initiation of cigarette smoking during the adolescence period are socio-demographic features, friendships, family members' habit of cigarette smoking, and curiosity, additionally having a chronic disease may also increase the inclination to smoking cigarettes. ${ }^{3}$ Adolescent stress caused by the process of treatment and follow-up due to a chronic disease may lead them to think that smoking cigarettes could help them relax, and the inclination of an adolescent to smoke cigarettes may increase. ${ }^{4}$ Chronic diseases are different from each other, and many factors such as the stress caused by a chronic disease, effects on daily life quality, duration of the treatment process, frequency and duration of 
the follow-up, enteral or parenteral nature of treatment, and hospitalization or an ambulatory treatment may cause an adolescent to exhibit risky behavior. On the other hand, the number of studies on the inclination of adolescents with a chronic disease to start and continue cigarette smoking is limited. In this study, two patient groups with the diagnosis of two different chronic endocrine diseases, which are type 1 diabetes mellitus (T1DM) and congenital adrenal hyperplasia $(\mathrm{CAH})$, were included, we aimed to examine the effects of these diseases on the inclination to smoke cigarettes. These diseases were selected since both of them are life-long, and the treatment method of one of them is via injection while the other is oral. To our knowledge this is the first study from Turkey in which the frequency of cigarette smoking in patients with a chronic disease differing from each other and the factors having an effect on that behavior are examined.

\section{Material and Methods}

One-hundred adolescents with a diagnosis of T1DM and 50 adolescents with a diagnosis of $\mathrm{CAH}$ aged 12 and above followed at the Pediatric Endocrinology Clinic at our hospital were included in the study group, and 100 healthy adolescents who applied to the Adolescent Outpatient Clinic within the same age group, with no chronic disease and no current medication use were included as the control group. Patients with additional diseases other than the diagnosis of T1DM and $\mathrm{CAH}$ were not included in the study. The patients with T1DM applied a subcutaneous insulin injection 4 times per day, controlled their blood glucose with a glucometer 5-8 times per day, and complied to a diabetic meal plan. The patients with CAH used oral pills 3 times per day. The lower limit of age was taken as 12 since it indicated the mid-phase of adolescence. After approval of the ethics committee of our hospital was obtained (Institutional Review Board Number:73799008), the survey on cigarette smoking was applied to all of the adolescents face to face during their routine controls after informed consent. The survey had been developed by researchers.

In the first part of the survey, socio-demographic features were questioned. For the study group, in addition to socio-demographic features, questions concerning the chronic illness were asked such as; at what age they were diagnosed with the disease, the treatment method of their disease, the effect of their disease on their daily life, and their attendance to their follow-up appointments for their disease.

In the second part of the survey, the adolescents both in the study and control group were asked open-ended questions about their exposure to cigarette smoking, whether there were any cigarette smokers in their family and who they were and, place of exposure to cigarette smoking. All of the adolescents were asked whether they had any knowledge of the harms of cigarette smoking, and those who had this knowledge were asked in an open-ended way where they obtained their knowledge of the harms of cigarette smoking and what they knew about the methods of quitting cigarette smoking.

In the third part of the survey, all of the adolescents were asked to state whether they smoked cigarettes, whether they ever tried cigarette smoking even if they were not current smokers, and what the most important factors in their behavior for not smoking cigarettes were.

In the fourth part of the survey, questions were included were to be answered only by the cigarette smoking adolescents. They were asked at what age they started cigarette smoking, whether there were any individuals or events causing them to start cigarette smoking, how often they smoked cigarettes, how long after getting up they smoked the first cigarette of the day, at what hours of a day they smoked more cigarettes, during which time of the day did they find cigarette smoking more satisfying, where they smoked cigarettes most, and where they got the cigarettes from. The cigarette smoking adolescents were also questioned about whether they had any thoughts for quitting, whether they had tried quitting before, and about their desire and motivation to quit. In this part of the survey, the adolescents included in the case group were also asked whether they thought that their disease had had an effect on their initiation of cigarette smoking, and whether they needed any support or not.

\section{Statistical Analysis}

Statistical analyses of the data obtained from the 
answers given by the adolescents on the survey were made through the IBM program SPSS for Windows Version 22.0. Numeric variables were demonstrated by mean \pm standard deviation, and the categorical variables by number and percentage. Whether there was any difference between the groups in terms of categorical variables was examined through the Chi-square test, and normality of the numeric variables through the Kolmogorov Smirnov test. The differences between the independent groups in terms of numeric variables were examined through the one-way ANOVA in case of proof of parametric test hypotheses, and through the Kruskal-Wallis test in case of no proof. The level of significance in the analysis results was taken as $\mathrm{p}<0.05$.

\section{Results}

Age of the patients with T1DM (55\% males) included in the study was $15.3 \pm 2.2$ years, of the patients with CAH ( $36 \%$ males) was $15.9 \pm 2.7$ years, and of the healthy adolescents ( $48 \%$ males) was $15.1 \pm 2.1$ years. There was no significant difference found between the groups in terms of age and gender $(p=0.12$ and $\mathrm{p}=0.09$, respectively). The median level of education of the case group was $10^{\text {th }}$ grade, and of the healthy adolescents was $9^{\text {th }}$ grade $(p=0.36)$, and there was no difference found between the groups in terms of success at school $(p=0.10)$. Educational level and professions of the parents were similar across the groups. Seventy-two percent of the mothers were housewives, $39.6 \%$ of the fathers were workmen, and the parents of $91.2 \%$ of the adolescents were alive and together. Ninety-six percent of the adolescents lived together with their family. Level of monthly income was low (less than 1500 TRY) for approximately 30\% of the families, and there was no difference across the groups $(p=0.89)$. Socio-demographic features of the cases are provided in Table I.

Both groups came to hospital for follow-up every 3 months. Ninety-five percent of the cases in both groups came for follow-up regularly. Forty-three percent of the patients with T1DM thought that their disease did not affect their life, while the rate was found to be $62 \%$ for the cases with CAH $(\mathrm{p}=0.09)$.

Half $(50.8 \%)$ of all of the cases within the study were exposed to cigarette smoking, while
$44 \%$ of those within the group with T1DM, $58 \%$ of those within the group with $\mathrm{CAH}$, and $54 \%$ of those within the healthy control group were exposed to cigarette smoking. While the places where these three groups were most frequently exposed to cigarette smoking were living spaces such as houses and dormitories, the rate of exposure to cigarette smoking in the living spaces for the $\mathrm{CAH}$ group and the healthy control group was higher than that of the T1DM group. The rate of exposure to cigarette smoking in streets for the $\mathrm{CAH}$ group $(27.6 \%)$ was higher than those of both the T1DM group (18.2\%) and the healthy control group (5.6\%). There was a statistically significant difference found in terms of the place of exposure to cigarette smoking $(\mathrm{p}=0.001)$.

Families of $58.8 \%$ of all of the cases included in the study had a cigarette smoking member, and it was seen that the cigarette smoking person in the families was most frequently the father. Ninety-three percent of the adolescents included in the study had some knowledge about the habit and harms of cigarette smoking. The answer most frequently given by the cases within the T1DM group about the harms of cigarette smoking was respiratory distress in $37.8 \%$ while the answer most frequently given by the cases within the CAH group and the healthy control group was the lung cancer, respectively by $32.6 \%$ and $36.7 \%$. There was a statistically significant difference found between the answers of the groups about the harms of cigarette smoking $(\mathrm{p}=0.038)$ (Table II).

It was seen that $28 \%$ of those with the knowledge of the habit and harms of cigarette smoking across the groups had obtained it at school, and $19.8 \%$ from their family. Hundred-fourteen $(45.6 \%)$ of all of the cases requested information about the harms of cigarette smoking, and most frequently (54.5\%) from a specialist. Eighty-four $(33.7 \%)$ of the 249 cases within our study had knowledge concerning the methods of quitting cigarette smoking. Twenty-five (30.9\%) of 81 adolescents who stated the known methods of quitting cigarette smoking wrote about the cigarette smoking cessation hotline, $22(27.2 \%)$ about the centers/institutions for quitting cigarette smoking, 16 (19.8\%) about eating sunflower seeds or chewing a gum, $11(13.6 \%)$ about the medicines, 2 (2.5\%) about taking up a new 
Table I. Socio-demographic Features of Cases

\begin{tabular}{|c|c|c|c|}
\hline & $\begin{array}{l}\text { Type } 1 \text { diabetes } \\
\text { mellitus group } \\
(n=100)\end{array}$ & $\begin{array}{l}\text { Congenital adrenal } \\
\text { hyperplasia group } \\
(\mathrm{n}=50)\end{array}$ & $\begin{array}{l}\text { Control } \\
\text { group } \\
(\mathrm{n}=100)\end{array}$ \\
\hline Average age (years) & $15.3 \pm 2.2$ years & $15.9 \pm 2.7$ years & $15.1 \pm 2.1$ years \\
\hline (minimum-maximum) & (12-21 years) & (12-22 years) & (12-25 years) \\
\hline Gender & 55 males & 36 males & 48 males \\
\hline$(\%)$ & 45 females & 64 females & 52 females \\
\hline $\begin{array}{l}\text { Level of education } \\
\text { (median) }\end{array}$ & $10^{\text {th }}$ grade & $\begin{array}{l}10^{\text {th }} \text { grade } \\
\text { ( } 5 \text { adolescents work in a job) }\end{array}$ & $\begin{array}{l}9^{\text {th }} \text { grade } \\
\text { (1 adolescent works in a job) }\end{array}$ \\
\hline \multirow[t]{6}{*}{ Mother's profession } & $78 \%$ housewives & $62 \%$ housewives & $71 \%$ housewives \\
\hline & $12 \%$ workmen & $14 \%$ workmen & $12 \%$ workmen \\
\hline & $2 \%$ self-employed & $8 \%$ health-care staff & $5 \%$ teachers \\
\hline & $1 \%$ health-care staff & $6 \%$ teachers & $4 \%$ health-care staff \\
\hline & $1 \%$ teachers & $2 \%$ self-employed & $3 \%$ self-employed \\
\hline & $\begin{array}{l}6 \% \text { at other public } \\
\text { services }\end{array}$ & $\begin{array}{l}8 \% \text { at other public } \\
\text { services }\end{array}$ & $5 \%$ at other public services \\
\hline \multirow[t]{8}{*}{ Father's profession } & $44 \%$ workmen & $30 \%$ workmen & $40 \%$ workmen \\
\hline & $25 \%$ self-employed & $32 \%$ self-employed & $36 \%$ self-employed \\
\hline & $5 \%$ police/soldiers & $12 \%$ police/soldiers & $8 \%$ police/soldiers \\
\hline & $5 \%$ teachers & $6 \%$ teachers & $1 \%$ teachers \\
\hline & $1 \%$ health-care staff & $14 \%$ at other public & $6 \%$ at other public services \\
\hline & $9 \%$ at other public services & services & $9 \%$ retired \\
\hline & $10 \%$ retired & $6 \%$ retired & \\
\hline & $1 \%$ unemployed & & \\
\hline $\begin{array}{l}\text { Number of siblings } \\
\text { (minimum-maximum) }\end{array}$ & 0-9 siblings & 1-3 siblings & 0-6 siblings \\
\hline \multirow[t]{3}{*}{ Togetherness of parents } & $\begin{array}{l}96 \% \text { both are alive and } \\
\text { together }\end{array}$ & $\begin{array}{l}92 \% \text { both are alive and } \\
\text { together }\end{array}$ & $\begin{array}{l}86 \% \text { both are alive and } \\
\text { together }\end{array}$ \\
\hline & $\begin{array}{l}3 \% \text { both are alive, the } \\
\text { case lives with the } \\
\text { mother. }\end{array}$ & $\begin{array}{l}6 \% \text { both are alive, the } \\
\text { case lives with the } \\
\text { mother. }\end{array}$ & $\begin{array}{l}9 \% \text { both are alive, the case } \\
\text { lives with the mother. }\end{array}$ \\
\hline & $\begin{array}{l}1 \% \text { both are alive, the } \\
\text { case lives with the } \\
\text { father. }\end{array}$ & $\begin{array}{l}2 \% \text { father of the case } \\
\text { is dead. }\end{array}$ & $\begin{array}{l}1 \% \text { both are alive, the case } \\
\text { lives with the father. } \\
3 \% \text { father of the case is dead. }\end{array}$ \\
\hline \multirow{5}{*}{$\begin{array}{l}\text { Monthly income of the } \\
\text { family }\end{array}$} & $27 \%<1500$ TRY & $28 \%<1500$ TRY & $32 \%<1500$ TRY \\
\hline & $39 \%$ 1500-2500 TRY & $40 \%$ 1500-2500 TRY & $33 \%$ 1500-2500 TRY \\
\hline & $22 \%$ 2500-3500 TRY & $18 \%$ 2500-3500 TRY & $19 \%$ 2500-3500 TRY \\
\hline & 4\% 3500-4500 TRY & $8 \%$ 3500-4500 TRY & 5\% 3500-4500 TRY \\
\hline & $8 \%>4500$ TRY & $6 \%>4500$ TRY & $11 \%>4500$ TRY \\
\hline
\end{tabular}


Table II. Responses from Cases about the Harms of Cigarette Smoking.

\begin{tabular}{lccc}
\hline $\begin{array}{l}\text { Responses given about } \\
\text { the harmful effects of } \\
\text { cigarette smoking }\end{array}$ & $\begin{array}{c}\text { Type } 1 \text { diabetes } \\
\text { mellitus group } \\
(\mathrm{n}=90) \\
(\%)\end{array}$ & $\begin{array}{c}\text { Congenital adrenal } \\
\text { hyperplasia group } \\
(\mathrm{n}=46) \\
(\%)\end{array}$ & $\begin{array}{c}\text { Control group } \\
(\mathrm{n}=90)\end{array}$ \\
\hline $\begin{array}{l}\text { Lung cancer } \\
\text { Respiratory distress }\end{array}$ & 24.4 & 32.6 & $(\%)$ \\
$\begin{array}{l}\text { Lung cancer and } \\
\text { respiratory distress }\end{array}$ & 37.8 & 21.7 & 36.7 \\
$\begin{array}{l}\text { Heart disease/ } \\
\text { vascular occlusion }\end{array}$ & 11.1 & 19.6 & 28.9 \\
$\begin{array}{l}\text { Lethality } \\
\text { Addictiveness }\end{array}$ & 6.7 & 2.2 & 21.1 \\
Negative effect on & 10 & 17.4 & 0 \\
the liver & 3.3 & 2.2 & 11.1 \\
Negative effect on & 1.1 & 0 & 0 \\
the kidneys & & & 0 \\
All & 2.2 & 2.2 & 0 \\
\hline
\end{tabular}

hobby, and $1(1.2 \%)$ about electronic cigarettes. There was no significant difference between the groups in terms of having the knowledge of the methods of quitting cigarette smoking and the methods used to quit cigarette smoking ( $\mathrm{p}=0.80$ and $\mathrm{p}=0.62$, respectively).

When the adolescents with a chronic disease and the healthy adolescents were asked whether they smoked cigarettes, $14(5.6 \%)$ of the 250 adolescents in total included within the study were cigarette smokers. While $1(1 \%)$ of the 100 patients within the T1DM group were cigarette smokers, 2 (4\%) of the 50 patients within the CAH group were cigarette smokers. Within the group of the healthy adolescents, $11(11 \%)$ of the 100 adolescents were cigarette smokers. There was a significant difference found between the groups in terms of cigarette smoking $(p=0.008)$, and the highest rate of cigarette smoking was seen in the healthy adolescents. Of the 14 cigarette smoking cases in total, 12 were males, 2 were females, the average age for initiation of cigarette smoking was $14.4 \pm 0.8$ years, and school success of 12 of them was medium-level. Educational level of mothers and fathers was generally at the level of primary school and secondary school. Either parent of $85.7 \%$ of all of the cigarette smoking cases was also a cigarette smoker. Economic status of the cigarette smoking cases was generally low, and the people who had an effect on their initiation of cigarette smoking were generally their parents and friends.

There was no significant difference found between the groups in terms of the percentages of trying and quitting cigarette smoking $(p=0.80)$. However, it was seen that rates of trying cigarette smoking in all of the adolescents included within the study, whether having a chronic disease or being healthy, were strikingly similarly $20 \%$, in other words, one out of every 5 adolescents had tried cigarette smoking. Seventy percent of the non-cigarette-smoker 236 adolescents in total stated that they did not smoke cigarettes since it was harmful to health (Table III).

\section{Discussion}

In our study, adolescents with chronic endocrine disease had lower cigarette use than healthy adolescents. The fact that most of the participating adolescents live together with their family, additional to the fact that adolescents with chronic endocrine disease are more anxious about their health, the rules that they should be careful about in their daily lives and the treatment plans they need to comply with, the worry that smoking can worsen the course of illnesses can be cited as reasons for reducing the tendency to smoke in 
Table III. Numbers and Percentages of Current Non-smoker Adolescents

\begin{tabular}{lccc}
\hline Current non-cigarette- smokers & $\begin{array}{c}\text { Type 1 diabetes } \\
\text { mellitus group } \\
(\mathrm{n}=99) \\
(\mathrm{n} / \%)\end{array}$ & $\begin{array}{c}\text { Congenital adrenal } \\
\text { hyperplasia group } \\
(\mathrm{n}=48) \\
(\mathrm{n} / \%)\end{array}$ & $\begin{array}{c}\text { Control group } \\
(\mathrm{n}=89) \\
(\mathrm{n} / \%)\end{array}$ \\
\hline $\begin{array}{l}\text { Never smoked } \\
\text { cigarettes. }\end{array}$ & $79 / 79.8$ & $39 / 81.3$ & $71 / 79.8$ \\
Smoked and then quitted & $20 / 20.2$ & $9 / 18.7$ & $18 / 20.2$ \\
\hline
\end{tabular}

adolescents with chronic disease. In addition, we believe that, in adolescents with diabetes, generalized health information in addition to counseling concerning the primary disease, by a multidisciplinary team (endocrinologist, diabetes nurse, dietitian, psychologist, etc.) may have also reduced cigarette use among adolescents in our study. At the same time, access to information on health issues of adolescents has increased with the easier access to information through tools such as the internet and television. The increase in the rate of informed access to health can make it easier for adolescents with chronic disease to learn the negative consequences of their illness and to reduce their smoking. Similar to the result of our study, in a study conducted by Potter K. et $\mathrm{al}^{5}$ in Canada on adolescents with T1DM between 13 and 18 years, rates of smoking cigarettes in adolescents with T1DM was similar to healthy adolescents. In the routine control of T1DM patients, the importance of informing patients about risky behaviors and the negative effects of these behaviors on diseases has been emphasized and is predicted as a result of the study. ${ }^{5}$ Another study conducted by Hogendorf et al ${ }^{6}$ in Poland with adolescents between 15 and 18 years with T1DM, found that adolescents with T1DM smoked less than adolescents in the control group.

Cigarette smoking is a type of risky behavior with a potential of inclination during adolescence. ${ }^{1,2}$ Conversely to the result of our study, there are studies in which chronic disease is seen as a factor that may increase the tendency to cigarette smoking. Within a study conducted by Suris et $\mathrm{al}^{7}$ in Switzerland with 7548 adolescents (760 with a chronic disease) aged between 16 and 20 years, health risk behaviors categorized in eight categories such as smoking, alcohol use, cannabis or illegal substance use, eating disorders, violence or antisocial behavior, early sexual activity; and smoking, cannabis use, and violent or antisocial behaviors in adolescents with chronic disease were found higher. It was stated that adolescents with a chronic disease had higher rates of over three or four health risk behaviors. In the same study, cigarette smoking was found to be 1.18 times higher among adolescents with a chronic disease than healthy adolescents. The reasons for this result were stated as adolescents with a chronic disease had more emotional stress, which made it easier to experience risky behaviors, and the absence of health risk screening and preventive counseling services apart from primary disease. Similarly, within another study conducted by Suris and Parera ${ }^{8}$ with 6952 adolescents (665 with a chronic disease) aged between 14 and 19 years, adolescents with a chronic disease were examined for their tendency to engage in risky behaviors such as smoking, alcohol use, illegal drug use and sexual activity and it was determined that smoking was more frequent in girls with a chronic disease, but it was similar to that of healthy ones in males.

It is known that most individuals who actively smoke cigarettes during adulthood had started during adolescence.1,2 Within the study conducted in the province of Tokat by Emekdar et $\mathrm{al}^{9}$ with 1069 students aged $14.1 \pm 2.4$ years, $46.7 \%$ of the high-school students started cigarette smoking at the age of 14 or below. Within our study, the age of initiation of cigarette smoking was $14.4 \pm 0.8$ years, and it was seen that the age of the initiation of cigarette smoking was between 15-17 years by the highest rate.

Reasons for starting cigarette smoking may be psychological or social depending on the 
age. ${ }^{10,11}$ Within two studies conducted in our country with adolescents, the reason for starting cigarette smoking was due to curiosity in 42.4$67 \% .{ }^{9,12}$ Within our study, the most important reason for starting cigarette smoking was also curiosity by $42.8 \%$.

Studies conducted have reported that a low level of academic performance, in addition to the low socio-economic and educational level of families, also increased the behavior of cigarette smoking. ${ }^{3,13}$ Similarly within our study, socio-economic and educational levels of the cigarette smoking adolescents were low. In addition, $85.7 \%$ of these cases had a medium-level academic performance.

Having a parents, siblings or friend who smokes and having a family member who smokes at home are also risk factors for adolescents becoming inclined to smoking cigarettes. ${ }^{3}$ Within a study conducted by Demir et al ${ }^{14}$ with adolescents aged between 15 and 20 years in Ankara, fathers were the most common people in their lives to be smokers $(50.4 \%)$, this was followed by friends $(32.9 \%)$. Within our study, $58.8 \%$ of the adolescents had a cigarette smoking family member. There was a cigarette smoking person in the family of 11 of 14 cigarette smoking adolescents, and $91 \%$ of these were fathers which is in line with the literature. Exposure to cigarette smoking - passive cigarette smoking - is an important public health concern both in the world and in Turkey. ${ }^{15}$ According to the conclusion of the Global Adult Tobacco Survey conducted in our country in 2012 , cafeterias by $26.6 \%$, restaurants by $12.9 \%$, public transport by $10.4 \%$, and health-care institutions by $3.8 \%$ were the places with exposure to cigarette smoking other than houses. ${ }^{16}$ Considering all of the groups within our study, it was seen that the places where $127(50.8 \%)$ of the 250 adolescents were most frequently exposed to cigarette smoking were their own living spaces such as homes and dormitories. For the T1DM and the control groups this was followed by cafeterias, (31.8\% and $11.1 \%$ respectively), whereas for the $\mathrm{CAH}$ group this was the streets in $27.6 \%$

According to the Global Adult Tobacco Survey conducted across the world in 2012, it was seen that $96.2 \%$ of the people aged 15 and above were aware that cigarette smoking caused serious diseases, and $97.7 \%$ of the respondents thought that cigarette smoking was the most important cause of lung cancer. ${ }^{16}$ Similarly when asked about the harms of cigarette smoking the responses given by the adolescents included within our study was lung cancer by $31 \%$, respiratory distress by $31 \%$, and both lung cancer and respiratory distress by $16.8 \%$. It was reported that $70 \%$ of adolescents obtained information concerning the harms of cigarette smoking at school according to the media in Global Youth Tobacco Survey. ${ }^{17}$ This rate was similar to that within our study.

Fighting against cigarette smoking, which is a serious public health concern, is of capital importance around the world. 3,14 Within the Global Youth Tobacco Survey conducted by Choi et $\mathrm{al}^{17}$ in Korea in 2013 with 4235 adolescents aged between 13 and 15 years, it was seen that $66.8 \%$ of the adolescents wanted to quit smoking cigarettes. In our study $8(72.7 \%)$ of the 11 adolescents had considered quitting smoking cigarettes. Rates of having tried cigarette smoking in all of the adolescents included within the study, whether they had a chronic disease or not, was similarly found to be $20 \%$. It was considered a pleasing result that $77 \%$ of them did not continue smoking. These results could imply that although both the healthy teens and those with a chronic illness started smoking, having a chronic disease put the adolescents off smoking cigarettes. More studies are needed on the reasons for cigarette smoking and for quitting cigarette smoking in adolescents with a chronic disease in order to support our present study.

Our study is the first study conducted on this subject in our country, and it indicates that cigarette smoking in the adolescents with a chronic disease is lower than that in the healthy adolescents. However, there is a need for more studies with a greater number of cases and chronic disease variability.

\section{REFERENCES}

1. Kim JA, Lee CY, Lim ES, Kim GS. Smoking cessation and characteristics of success and failure among female high-school smokers. Jpn J Nurs Sci 2013; 10: 68-78.

2. Çavdar S, Çetinkaya Sümer E, Eliaçık K, et al. Izmir'de liseye devam eden ergenlerin sağgl k davranışları. Türk Pediatri Arşivi 34-22: 2016. 
3. Sylvestre MP, Wellman RJ, O'Loughlin EK, Dugas EN, O'Loughlin J. Gender differences in risk factors for cigarette smoking initiation in childhood. Addictive Behaviors 2017; 72: 144-150.

4. Huurre TM, Aro HM. Long-term psychosocial effects of persistent chronic illness. A follow-up study of Finnish adolescents aged 16 to 32 years. Eur Child Adolesc Psychiatry 2002; 11: 85-91.

5. Potter K, Luca P, Pacaud D, et al. Prevalence of alcohol, tobacco, cannabis and other illicit substance use in a population of Canadian adolescents with type 1 diabetes compared to a general adolescent population. Paediatr Child Health 2018; 23: 185-190.

6. Hogendorf AM, Fendler W, Sierosławski J, et al. Alcohol and cigarette use among adolescents with type 1 diabetes. Eur J Pediatr 2017; 176: 713-722.

7. Suris JC, Michaud PA, Akre C, Sawyer SM. Health risk behaviors in adolescents with chronic conditions. Pediatrics 2008; 122: e1113-1118.

8. Suris JC, Parera N. Sex, drugs and chronic illness: health behaviors among chronically ill youth. Eur J Public Health 2005; 15: 484-488.

9. Emekdar G, Çıtıl R, Önder Y ve ark. Tokat ili ortaokul ve lise öğrencilerinde sigara içme prevalansı ve etkileyen faktörler. Çağdaş Tıp Dergisi 2017; 7: 58-66.

10. Hruba D, Zaloudikova I. Why to smoke? Why not to smoke? Major reasons for children's decisions on whether or not to smoke. Cent Eur J Public Health 2010; 18: 202-208.
11. Pederson LL, Koval JJ, O'Connor K. Are psychosocial factors related to smoking in grade- 6 students? Addictive Behaviors 1997; 22: 169-181.

12. Erbaydar T, Lawrence S, Dağlı E, Hayran O, Collishaw NE. Influence of social environment in smoking among adolescents in Turkey. Eur J Public Health 2005; 15: 404-410.

13. Moor I, Rathmann K, Lenzi M, et al. Socioeconomic inequalities in adolescent smoking across 35 countries: a multilevel analysis of the role of family, school and peers. Eur J Public Health 2015; 25: 457-463.

14. Demir M, Karadeniz G, Demir F, et al. The impact of anti-smoking laws on high school students in Ankara, Turkey. J Bras Pneumol 2015; 41: 523-529.

15. Ekerbiçer HC, Çelik M, Güler E, Davutoğlu M, Kılınç M. Evaluating environmental tobacco smoke exposure in a group of Turkish primary school students and developing intervention methods for prevention. BMC Public Health 2007; 7: 202.

16. Public Health Institution of Turkey. Global Adult Tobacco Survey Turkey 2012. Ankara: Anil Matbaa Ltd. Şti., 2014.

17. Choi S, Kim Y, Lee J, Kashiwabara M, Oh K. Tobacco use among students aged 13-15 years in South Korea: The 2013 Global Youth Tobacco Survey. J Prev Med Public Health 2017; 50: 60-65. 